\title{
Economic impact of transportation infrastructure investment under the Belt and Road Initiative
}

\section{Zhenhua Chen ${ }^{1} \oplus \cdot$ Xinmeng $\mathrm{Li}^{2}$}

Received: 5 August 2020 / Revised: 11 February 2021 / Accepted: 13 May 2021 /

Published online: 20 July 2021

(๑) The Author(s), under exclusive licence to Springer-Verlag GmbH Germany, part of Springer Nature 2021

\begin{abstract}
China launched an ambitious strategy known as the Belt and Road Initiative (BRI) in 2013 with an objective to promote regional economic growth and integration. The initiative was implemented primarily through massive investment in transportation infrastructure development among the Belt and Road countries to improve transportation connectivity and reduce trade costs. While such a strategy has been implemented for more than seven years, it remains unclear to what extent the investment of transportation infrastructure has affected the regional economic performance in various countries. To clarify this question, this study provides an in-depth assessment of BRI investment in transportation infrastructure using a computable general equilibrium (CGE) model. Different from previous studies, the regional economic impact was evaluated through CGE simulations based on the actual investment data obtained from various sources. In addition, both the change of intraregional and interregional trade costs as a result of BRI transportation infrastructure investment was estimated. The results show that the transportation infrastructure investment in BRI has generated different impacts among regions. In particular, China, Central and West Asian countries have gained significant growth in GDP, employment, and economic welfare, whereas the economic impact of transportation infrastructure investment in the Central and West Europe is relatively minor. Overall, the research findings provide important policy implications for future transportation infrastructure investment in BRI countries and beyond.
\end{abstract}

Zhenhua Chen

chen.7172@osu.edu

Xinmeng Li

lixinmeng@se.is.tohoku.ac.jp

1 City and Regional Planning, Knowlton School of Architecture, The Ohio State University, 275 West Woodruff Ave, Columbus, OH 43210, USA

2 Graduate School of Information Sciences, Tohoku University, Aoba 6-3-09, Aramaki, Aoba-ku, Sendai, Miyagi 980-8579, Japan 


\section{Introduction}

The Belt and Road Initiative (BRI), as a global development strategy of China, has received increasing attention since its implementation in 2013. The objective of this strategy is to facilitate economic and cultural exchange and integration among different countries in Asia, Africa, the Americas, Middle East, and Europe to achieve coordinated regional development. One key focus of BRI is to promote infrastructure development through a consistent pace of investment. The ultimate goal is to establish an "international community with shared interests, destiny, and responsibility" through an interconnected infrastructure system and trade cooperation (Zhang 2018).

According to President Xi Jinping, the BRI is implemented to improve the international cooperation between China and other countries through five dimensions: policy coordination, infrastructure connectivity, financial partnership, unimpeded trade, and people to people bonds. In particular, infrastructure connectivity refers to the development of railways, highways, ports, air routes, telecommunications, and energy pipelines in order to create an infrastructure network to boost connectivity and promote market integration (Centre For Geopolitics and Security in Realism Studies 2016).

The BRI is open to all countries. The number of participating countries has increased substantially since its deployment. By the end of 2020, 138 countries (as illustrated in Fig. 1) and 31 international organizations have signed MOU with China. The trend of infrastructure investment in the transport sector in BRI countries is illustrated in Fig. 2. It shows that during 2014-2018, the investment in transportation infrastructure from China has increased substantially. In addition, it is expected that the world's infrastructure investment is likely to reach $\$ 1.3$ trillion by

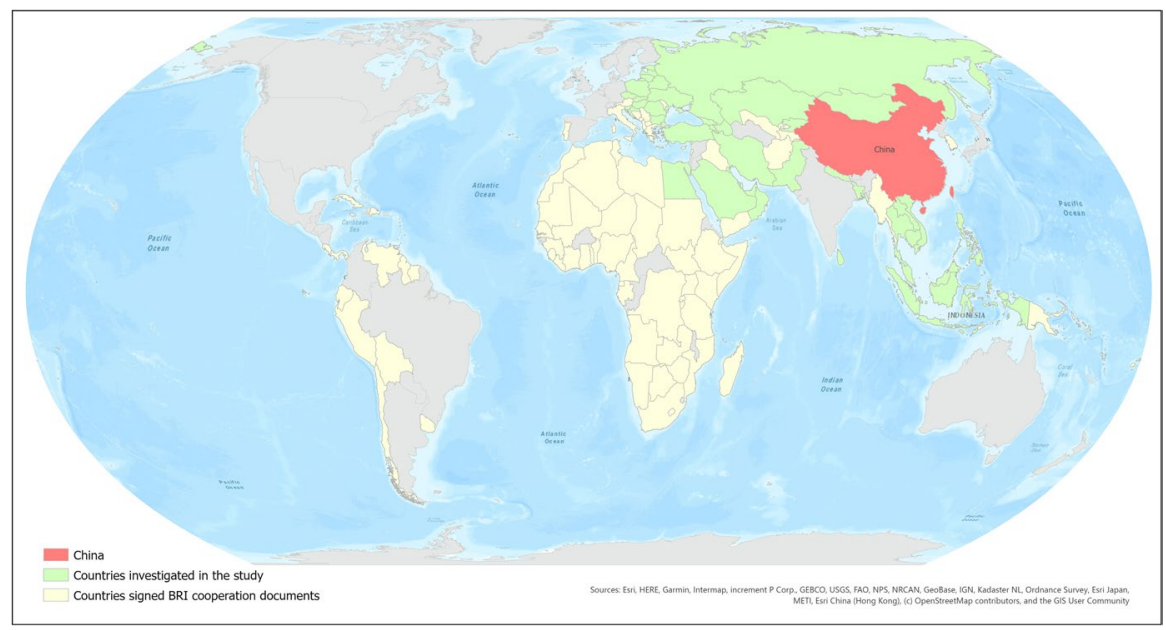

Fig. 1 Countries signed BRI Cooperation Documents with China. Source: Belt and Road Portal: https:// www.yidaiyilu.gov.cn/xwzx/roll/77298.htm 


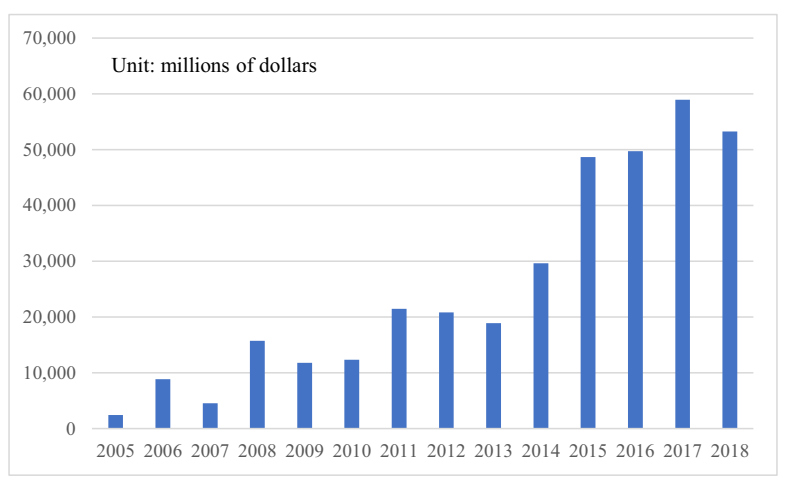

Fig. 2 BRI-related investment in transportation sector from Chinese corporations. Source: American Enterprise Institute

2027 (Stanley 2018). ${ }^{1}$ These investments will facilitate the development of a wide range of infrastructure systems, such as transportation, oil and gas pipelines, telecommunication, and power system (American Enterprise Institute 2018). According to the China Global Investment Tracker of the American Enterprise Institute, during 2014-2020, there are 58 records of outward direct investment of \$40.4 billion in the transport sector under the strategy of BRI. These investments were mainly from China's state-owned enterprises, such as the China Communications Construction and the China Railway Construction. Meanwhile, 304 construction contracts related to the transportation sector were signed during the period. Key investors include China Railway Construction, China Energy Engineering, China Railway Engineering, and Power Construction Corporation of China.

To promote regional trade flow and economic development, the BRI consists of two main strategies: development of surface physical infrastructure, which refers to the "belt," and an improvement of maritime transportation, which is known as "maritime silk road." Specifically, the following land infrastructure corridors were

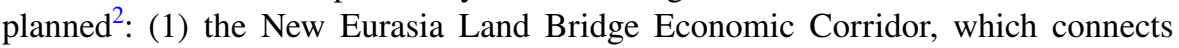
Western China with countries, such as Kazakhstan, Russia, and Western Europe; (2) the China-Mongolia-Russia Economic Corridor; (3) China-Central Asia-Western Asia Economic Corridor, which connects Western China with Turkey; (4) China"Indochina Peninsula," which links China with Southeast Asian countries, such as Cambodia, Laos, Myanmar, Viet Nam, and Thailand; and (5) China-Pakistan Economic Corridor.

\footnotetext{
${ }^{1}$ The estimate was predicted in the pre-COVID-19 era. However, one should note that the COVID-19 is likely to a long-lasting influence on infrastructure investment. On one hand, the pandemic may slow down the investment in short-term due to the requirement of social distancing and a temporary suspension of project. On the other hand, infrastructure investment may experience a substantial growth in the recovery period as a response of government stimulus spending.

${ }^{2}$ The Bangladesh-China-India-Myanmar Economic Corridor, which was originally proposed in 2015 by China, was dropped from the list of corridors in 2019, due to the opposition of India.
} 
While the BRI was endorsed by more than 130 countries, skepticism and opposition also exist. Some scholars, for instance, Chellaney (2017) argued that the BRI is essentially a neocolonial strategy that China aims to take over assets and natural resources and to expand its military and naval presence through the practice of debttrap diplomacy to fund the initiative's infrastructure projects. However, other scholars, such as Singh (2020), held a different view, who believed that China provides unconditional financing opportunities for the countries that face hostility from the US and its allies to develop infrastructure systems. As a result, it remains unclear to what extent the investment from China has affected the economic performance of different partner countries.

The objective of this study is to provide a comprehensive assessment of the economic impact of infrastructure investment in the transportation sector under the BRI. Based on the data obtained from various sources, including American Enterprise Institute (AEI), the World Bank, and the Organisation for Economic Co-operation and Development (OECD), the influence of trade cost change as a response to transportation infrastructure investment is estimated by different regions. The indirect economic impacts of transportation infrastructure are evaluated using the Global Trade Analysis Project (GTAP) model by implementing a shock of trade cost reduction, which is caused by improved infrastructure connectivity and reduced transportation. The assessment helps us better understand the economic impacts of the BRI investment in transportation infrastructure. The research outcomes may also provide implications for decision-makers and investment agencies to improve the efficiency of their decision-makings on future investment.

The rest of the paper is organized as follows. "Literature review" section identifies the research gaps through a thorough literature review. "Data" and "Methodology" sections introduce the data and methodology, respectively. "Simulation results" section presents the results of computable general equilibrium (CGE) simulations, whereas "Conclusion" section summarizes and concludes.

\section{Literature review}

Despite the massive and rapid investment and project implementation, the empirical understanding of the economic impact resulting from transportation infrastructure investment in BRI remains unclear. Part of the reason is due to the complexity of measurement at such a large geographic scale. The following review focuses on the generic evaluation of the economic impact of infrastructure and the specific evaluations of transportation infrastructure projects in the context of BRI.

\section{Economic impacts of infrastructure}

Traditionally, the role of infrastructure in economic growth and regional development was evaluated through the change of connectivity and accessibility of the markets as a response to infrastructure development (Lall 2007; Francois and Manchin 2013; Chong et al. 2019). Moreover, the improvement of infrastructure quality is likely to improve not only the productivity of existing firms, but it may also facilitate 
the formation of new firms (Puga 2002). Several studies, such as Aschauer (1989, $1990,1994)$ revealed that the US public expenditure on transportation infrastructure plays a critical role in promoting productivity. In addition, Stough and Rietveld (1997) also revealed that infrastructure is critical for foreign firms to determine their location, which hence, may indirectly promote the growth of the regional economy. From the perspective of New Economic Geography, infrastructure improvement leads to a reduction of transportation costs, which may facilitate an industrial agglomeration and change of the total demand in the markets. For instance, Chen et al. (2016) found that rail infrastructure investment in China has stimulated the growth of the economy through increased demand and output expansion. Using a spatial panel model, Chen and Haynes (2014) pointed out that surface transportation infrastructure in the US northeast corridor generates positive spillover effects on regional GDP.

A number of studies have also confirmed that the improvement of transportation infrastructure has been a major factor in reducing international trade costs (Limao and Venables 2001; Donaldson 2018). Brooks and Hummels (2009) pointed out that infrastructure construction plays an important role in trade expansion in Asia. The development of transportation infrastructure through the BRI is likely to have a significant impact on reducing shipment time and trade costs (de Soyres et al. 2020). Their study revealed that shipment time and trade costs have reduced by $1.7-3.2 \%$ and $1.5-2.8 \%$ due to transport infrastructure development in BRI countries, respectively.

In addition, scholars also found that the impact of trade on labor markets is likely to be substantial given the development of economic globalization. According to Melitz (2003), trade liberalization can facilitate the efficiency of intra-industry resource allocation, which thus may increase the labor demand and wage rate. For instance, through integrating the job-matching theory with the Melitz model, Felbermayr et al. (2011) revealed that trade liberalization could lower unemployment and raise real wages since active firms tend to be more productive and thus are likely to search for workers more intensively. However, other scholars, such as Egger and Kreickemeier $(2009,2012)$, indicated that the unemployment rate is likely to be higher under trade liberalization since firms may offer higher wages, which may lead to lower labor demand. As a result, it remains unclear to what extent the improvement of the trade environment (e.g., a reduction of trade cost and trade liberalization) may affect the macroeconomy.

\section{The impact of BRI investment}

Many empirical studies have confirmed that transport infrastructure projects in the BRI countries promote greater regional and interregional connectivity and international trade (Chan 2018; Sheu and Kundu 2018; Wang et al. 2020). Some scholars, such as Villafuerte et al. (2016), Zhai (2018), and Mukwaya and Mold (2018), assessed the economic impact of infrastructure development in belt and road countries using various methods, including both econometric analysis and CGE analysis. As the state-of-the-art impact assessment tool, CGE has been extensively adopted 


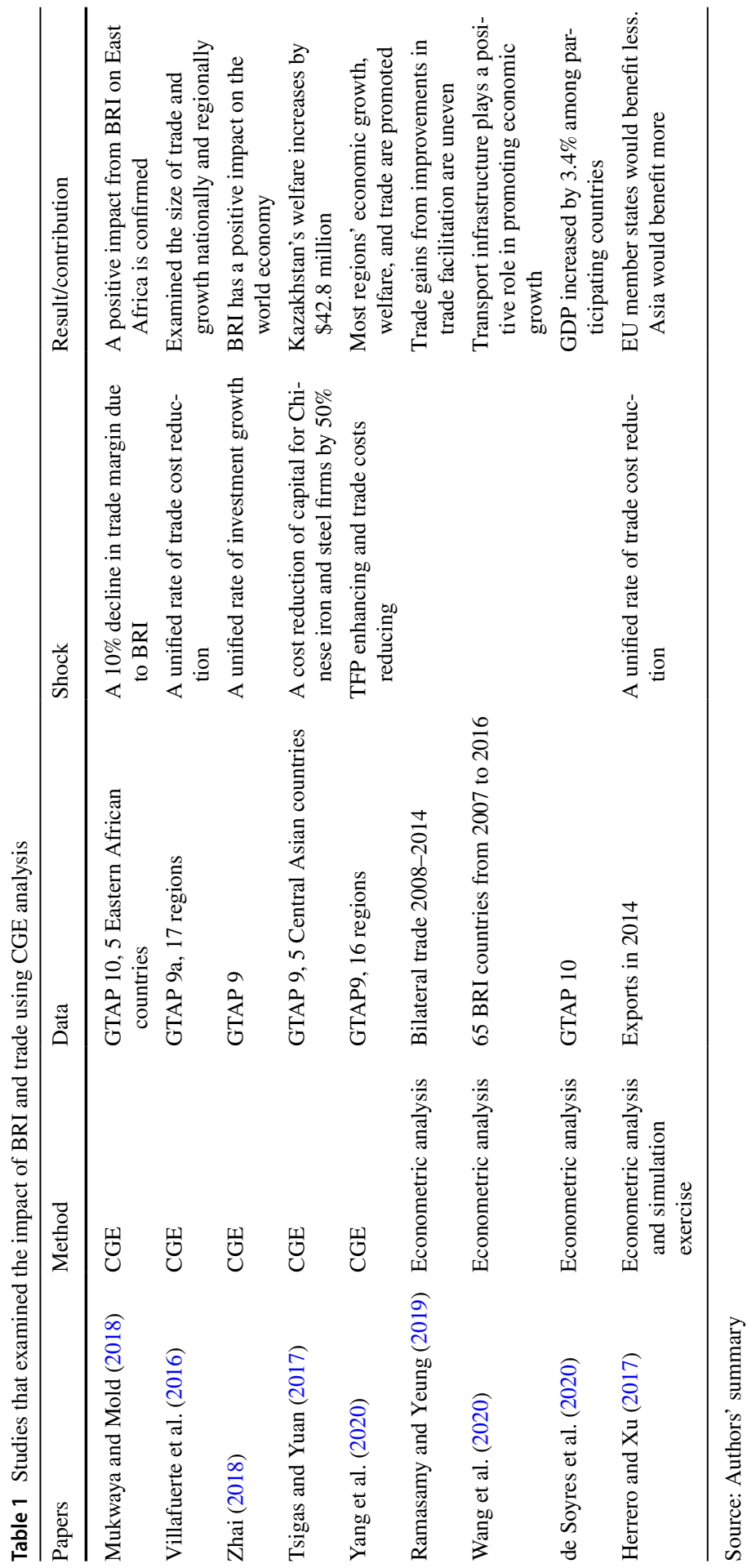


for the economic impact evaluation of BRI-related policies. Table 1 summarizes the relevant studies using CGE analysis. For instance, Mukwaya and Mold (2018) revealed that the reduction of trade margin as a result of BRI investment contributes to a $0.4-1.2 \%$ growth of the economy in East Africa. Wen and Tsigas (2017) evaluated the economy-wide impact of China's overseas investment in the iron and steel sector under BRI using CGE. Based on the assumption that the cost of capital for Chinese iron and steel firms would decrease by $50 \%$ due to the influence of BRI, their analysis revealed that economic welfare would increase by $\$ 4.78$ million in Kazakhstan. Although these studies provided some initial efforts to disclose the economic impact of BRI-related investment, one major limitation of these studies is that nearly all the CGE simulations were conducted based on hypothetical scenarios and magnitude of shocks. For instance, Villafuerte et al. (2016) analyzed the economic impact of infrastructure by assuming that the shocks to the economy were driven by a reduction of trade margin at a unified rate across all regions. Their findings showed that a $25 \%$ reduction in international road transport margin and a $5 \%$ reduction in sea transport margin would lead to an overall positive effect on GDP growth in Asia, and the economic welfare is likely to increase by $\$ 94$ billion. Similarly, Zhai (2018) evaluated the impact of infrastructure investment of BRI by assuming the investment growth rate is identical across all the regions. Also, Yang et al. (2020) estimated the effect of infrastructure investment on total factor productivity (TFP) enhancement and trade cost reduction. A significant difference between their research and ours is that they assumed three scenarios where the infrastructure investment demand gap can be fulfilled to certain degrees. Their results showed that BRI would generate a significant benefit to the world economy. One should note that while the results of these CGE analyses may be useful to gain a general understanding of the impact of certain BRI-related policies, these outcomes have limited implications for real-world planning practice and decision-making as the linkage between the actual infrastructure investments may affect the economy was not examined explicitly.

Overall, while a plethora of studies has attempted to evaluate the economic impact of transportation infrastructure, there is still a lack of understanding of the economic impacts of infrastructure investment in BRI based on realistic scenarios and data. In addition, it remains unclear to what extent the economic benefits of transportation infrastructure vary among different BRI countries, and to what extent the impacts vary among different sub-regions. To fill these research gaps, our study provides a comprehensive assessment of the economic impact of BRI transportation infrastructure investment from an ex-post perspective, based on the actual investment data collected from various data sources. Our objective is to provide, for the first time, a more realistic view of the impacts of China's BRI investment on the economy and welfare of the member countries. Through a careful estimation of the effect on trade cost change generated by transportation infrastructure investment, the CGE assessment enables us to capture various impacts, not only by different countries and regions, but also the different effects from both intraregional and interregional trade cost reductions, as well as the short-run versus the long-run effects. Such an evaluation enables us to gain a closer understanding of the impact of the BRI transportation infrastructure investment on the integration of regional markets in globalization. 
Table 2 Classifications of regions and economies under BRI

\begin{tabular}{ll}
\hline Region (no. of countries/regions) & Economies in BRI projects \\
\hline Central and West Asia (15) & United Arab Emirates (UAE), Armenia, Azerbaijan, Bahrain, \\
& Egypt, Georgia, Iran, Kazakhstan, Kyrgyzstan, Kuwait, \\
& Mongolia, Oman, Qatar, Saudi Arabia, Turkey \\
Central and East Europe (11) & Bulgaria, Czech, Estonia, Croatia, Hungary, Lithuania, Latvia, \\
& Poland, Romania, Slovakia, Slovenia \\
Eastern European non-EU members (3) & Belarus, Russian Federation, Ukraine \\
South and Southeast Asia (13) & Bangladesh, Brunei Darussalam, Indonesia, Sri Lanka, \\
& Cambodia, Lao PDR, Malaysia, Nepal, Pakistan, Philippines, \\
& Singapore, Thailand, Viet Nam \\
China (1) & P.R. China \\
Rest of the world (97) & All the rest of the countries/regions in the world \\
\hline
\end{tabular}

Source: Authors' classification

\section{Data}

Our assessment of the transportation infrastructure investment focuses on 42 Eurasian countries, which are the primary member countries of the BRI. As illustrated in Table 2, the assessments include six regions: 15 countries in Central and West Asia, 11 Central and East European nations, 3 Eastern European non-EU member countries, 13 South and Southeast Asian countries, China, and the rest of the world. ${ }^{3}$ The rationale of such aggregation is based on data availability, which does not reflect any geopolitical consideration.

The data used for this assessment covers the period 2006-2018. Specifically, the trade cost data were collected from the World Bank UNESCAP Trade costs Database. ${ }^{4}$ The dataset provides estimates of symmetric bilateral trade costs by sectors for 208 countries, which was calculated using the Inverse Gravity Framework. Other variables, such as GDP, population, the quality index of transportation infrastructure, tariff, and the exchange rate of different countries, were collected from the World Bank Open Data Website. The data of transportation infrastructure investment were obtained from both the World Bank Open Data ${ }^{5}$ and OECD. ${ }^{6}$ Although the scale of the data is somewhat different between the two sources, they are relevant and valuable as the OECD data provides detailed statistics of transport infrastructure investment in countries in Central and West Asia, Central and East Europe, Eastern European non-EU members, and China, whereas the data of South and Southeast Asia is more consistent from the World Bank. Hence, the OECD data was adopted

\footnotetext{
3 To capture the economic and trade relationships of mainland China with other countries, the literature generally considers China's Special Administrative Regions of Macao and Hong Kong and Taiwan, China as independent economic entities (Zhai 2018; de Soyres et al. 2020; Yang et al. 2020). Hence, to be consistent with the previous studies, they were included in the Rest of the World account.

${ }^{4}$ https://www.unescap.org/resources/escap-world-bank-trade-cost-database

5 https://data.worldbank.org/indicator/IE.PPI.TRAN.CD

6 https://data.oecd.org/transport/infrastructure-investment.htm
} 
to estimate the trade cost elasticity among countries in Central and West Asia, Central and East Europe, Eastern European non-EU members, and China, whereas the World Bank data was adopted to estimate the elasticity of the trade costs among the South Asian, the Southeast Asian countries, and other regions. In addition, we also introduced a dummy variable to capture the effect of the free trade agreement (FTA) on the change of trade cost, the data of which was collected from the Regional Trade Agreement Database offered by the World Trade Organization. ${ }^{7}$ The variable is coded as one if a bilateral FTA was established between two countries in year $t$.

\section{Methodology}

The impact assessment is implemented in two steps. In step one, the elasticity of trade cost is estimated using regression analysis. Then, the level change of trade cost in different regions is calculated based on the estimated trade cost elasticity and the volume of actual transportation investment. In step two, the changes in trade cost in different regions were adopted as the impact drivers for the CGE simulation. The macroeconomic outcomes as a result of the CGE shocks of trade cost change among BRI countries are then summarized and compared.

\section{Estimation of trade cost change}

\section{Step 1 estimating elasticity of trade cost}

The elasticity of trade cost change as a response to transportation infrastructure investment is estimated through the followingregression model, following Francois et al. (2009):

$$
\begin{aligned}
\ln \tau_{i, j, t}=\beta_{0}+\beta_{1} \ln p G D P_{i, t}+ & \beta_{2} \ln p G D P_{j, t}+\beta_{3} \ln t a r_{i, t}+\beta_{4} \ln t a r_{j, t} \\
& +\beta_{5} \ln I N F_{i, t}+\beta_{6} I N F_{j, t}+F T A_{i j}+\varepsilon_{i, j, t}
\end{aligned}
$$

where $i$ and $j$ represent region $i$ and $j$, and $t$ denotes the time period. In the regression model, $\tau_{i, j, t}$ denotes the trade cost from region $j$ to region $i$ in year $t$, which is expressed in a tariff-equivalent form (share of CIF prices), $\ln p G D P_{j, t}$ represents the logged GDP per capita of the country in region $j, \operatorname{tar}_{i, t}$ denotes tariff in region $i$, and $I N F_{i, t}$ represents the value of infrastructure investment. The elasticity of trade cost with respect to transportation infrastructure investment in country $i$ (country $j$ ) is denoted as $\beta_{5}\left(\beta_{6}\right) . F T A_{i j}$ is a dummy variable which equals to one if the two countries are in the same free trade area, otherwise $F T A_{i j}$ was equal to zero. The estimated results are summarized in Table 3.

The regression results show that the estimated coefficient of transportation infrastructure investment on intra-regional trade cost varies substantially among different O.D. pairs. The average trade cost elasticity based on the estimate of all samples is -0.04 , suggesting that a $1 \%$ increase in transportation infrastructure investment

\footnotetext{
7 http://rtais.wto.org/UI/PublicMaintainRTAHome.aspx
} 


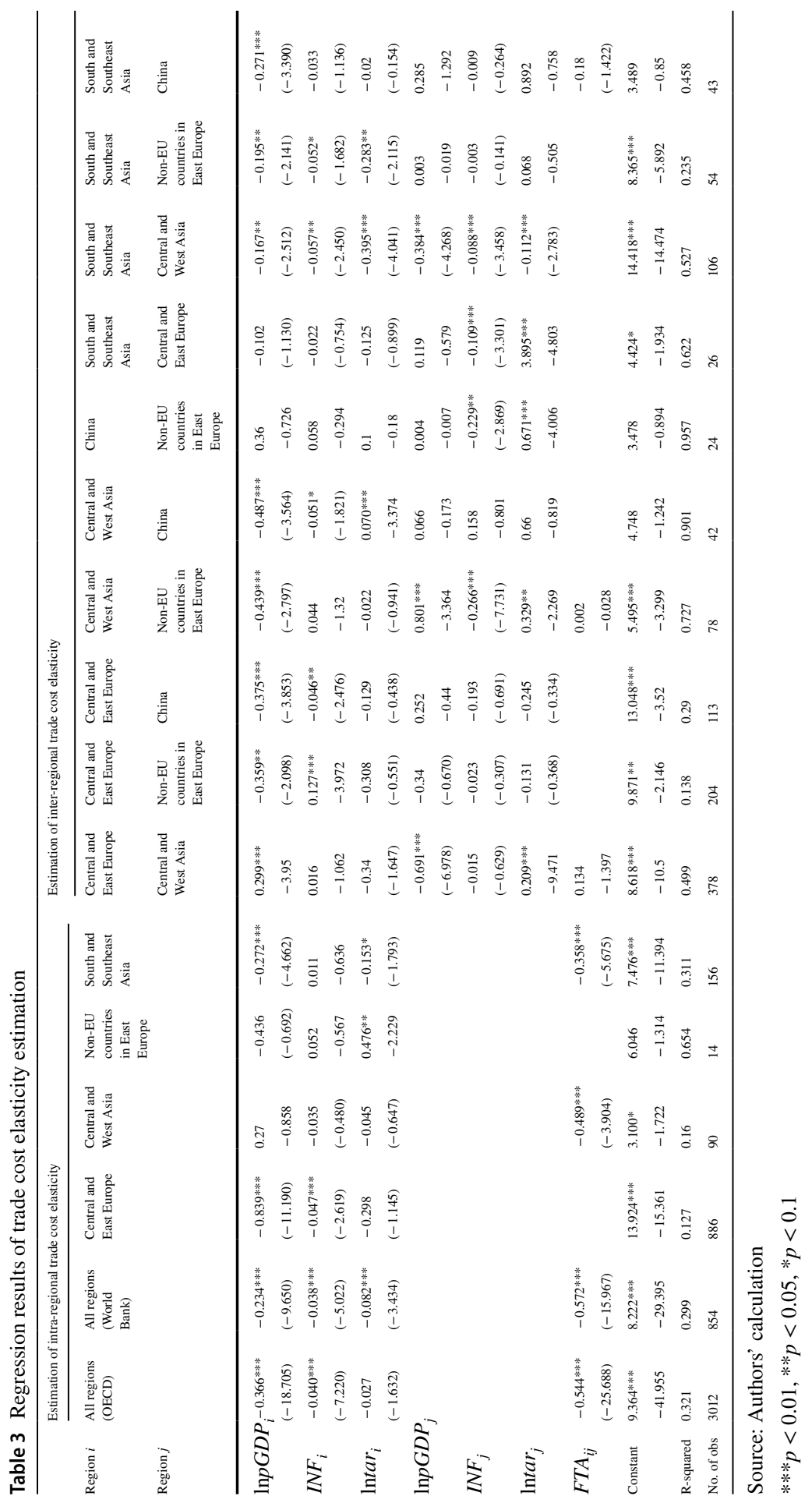


is associated with $0.04 \%$ reduction of trade cost, ceteris paribus. In terms of the intraregional trade cost elasticity, only the estimate of the Central and East Europe was found to be statistically significant, with a slightly higher value of -0.047 as compared with the overall estimate. The insignificant estimate of other regions may be due to various reasons, such as the lack of sufficient data to capture significant variations. Hence, we assume that the intraregional elasticities of trade cost for the remaining regions, such as Central and East Europe, Central and West Asia, Central Eastern European non-EU members, and China, are equal to the value of the overall estimate based on the OECD data. The elasticities of trade cost between South and Southeast Asia and other regions are equal to the estimate based on the World Bank dataset. In terms of the bilateral interregional elasticities of trade cost, the results show that that the estimated coefficients vary substantially among different regions. Similarly, for those regions with insignificant estimates, we also assume that the elasticity is equal to the mean value estimated based on the overall sample dataset. $^{8}$ The final elasticities of trade cost adopted for the analysis are summarized in Table 4.

\section{Step 2 calculating transportation infrastructure investment in BRI}

One of the major challenges of estimating the transportation infrastructure investment under the BRI is data limitation. This is because the assessment involves various developing countries, among which the data quality and availability can be a major issue. To address this challenge, we estimated the growth of transportation infrastructure investment using data obtained from different sources. Our assessment focuses on the Chinese overseas investment in transportation infrastructure-related projects. $^{9}$

Specifically, we first estimated the transportation infrastructure investment in the base year of 2013, the year when the BRI was launched. It was estimated based on the information collected from the Asian Development Bank (ADB). ${ }^{10}$ In addition, given that the future need of transportation infrastructure investment is expected to account for $34.5 \%$ of the total infrastructure investment in Asia (Asian Development

\footnotetext{
8 This also applies to the trade cost elasticity between Central and East Europe and Central Eastern European non-EU members, as a positive estimate was found in this case. Such a result could be attributed to the limitation of data.

9 The key data of infrastructure investment was obtained from the China Global Investment Tracker (CGIT) database. It contains investment and construction transactions over $\$ 100$ million. The investments were mainly from the Chinese corporate sources, and no trade, lending, or bond transactions were included (Scissors 2020).

${ }^{10}$ For instance, given that infrastructure investment from 2010-2014 accounts for 4.8\% of GDP in South Asia, 2.6\% of GDP in Southeast Asia, 2.9\% of GDP in Central and West Asia, respectively, the ratios were adopted for the calculation of the transportation infrastructure investment in 2013. The data is obtained from https://www.adb.org/node/228891.
} 
Table 4 Estimated elasticities of trade cost as a response to the change of transportation infrastructure investment from China

\begin{tabular}{lllll}
\hline Region of origin $(i)$ & Region of destination $(j)$ & Type & Coef. $i$ & Coef. $j$ \\
\hline Central and East Europe & Central and West Asia & Inter-region & -0.040 & -0.040 \\
Central and East Europe & Non-EU countries in East Europe & Inter-region & -0.040 & -0.040 \\
Central and East Europe & China & Inter-region & -0.046 & -0.040 \\
Central and West Asia & Non-EU countries in East Europe & Inter-region & -0.040 & -0.266 \\
Central and West Asia & China & Inter-region & -0.051 & -0.040 \\
China & Non-EU countries in East Europe & Inter-region & -0.040 & -0.229 \\
South and Southeast Asia & Central and East Europe & Inter-region & -0.038 & -0.109 \\
South and Southeast Asia & Central and West Asia & Inter-region & -0.057 & -0.088 \\
South and Southeast Asia & Non-EU countries in East Europe & Inter-region & -0.052 & -0.038 \\
South and Southeast Asia & China & Inter-region & -0.038 & -0.038 \\
Central and East Europe & Central and East Europe & Intra-region & -0.047 & -0.047 \\
Central and West Asia & Central and West Asia & Intra-region & -0.040 & -0.040 \\
Non-EU countries in East Europe & Non-EU countries in East Europe & Intra-region & -0.040 & -0.040 \\
South and Southeast Asia & South and Southeast Asia & Intra-region & -0.038 & -0.038 \\
\hline
\end{tabular}

Source: Authors' calculation

$* * * \mathrm{p}<0.01$

$* * \mathrm{p}<0.05$

$* \mathrm{p}<0.1$

and Bank 2015), ${ }^{11}$ the volume of transportation infrastructure investment in Asian countries in 2013 can be estimated through the following equation:

$$
I N F_{m, 2013}=G D P_{m, 2013} \times r_{I N F} \times r_{t r a n}
$$

where $r_{I N F}$ denotes the ratio of infrastructure investment over GDP and $r_{\text {tran }}$ denotes the ratio of investment in transportation over the total infrastructure investment. The data on transportation infrastructure investment in European countries were collected from OECD. ${ }^{12}$ Hence, the growth of investment in transportation infrastructure in country $m$ ( $\left.r_{m}^{\text {increase }}\right)$ in the period $2014-2020$ can be calculated as follows:

$$
r_{m}^{\text {increase }}=\frac{\sum_{t}^{2014-2020} I N F_{m, t}^{B R I}}{I N F_{m, 2013}}
$$

where $I N F_{m, t}^{B R I}$ represents the investment of infrastructure in the transportation sector. The specific investment in the transportation sector was obtained from the China Global Investment Tracker (CGIT) database from AEI. ${ }^{13}$ In the end, the growth rates

\footnotetext{
11 https://data.adb.org/dataset/infrastructure-needs-asia-and-pacific

12 ehttps://data.oecd.org/transport/infrastructure-investment.htm

13 The CGIT database provides both statistics of Chinese investment both by the actual investment and construction contracts. The former was adopted for the assessment. More details could be found at https://www.aei.org/china-global-investment-tracker/.
} 
Table 5 The growth of transportation infrastructure investment from the Chinese corporation through BRI projects among different countries

\begin{tabular}{lllll}
\hline ID & Country & $\begin{array}{l}\text { Investment of trans- } \\
\text { portation in 2013 } \\
\text { (million \$) }\end{array}$ & $\begin{array}{l}\text { Investment of transporta- } \\
\text { tion in BRI 2014-2020 } \\
\text { (million \$) }\end{array}$ & $\begin{array}{l}\text { Increasing } \\
\text { ratio with BRI } \\
\text { investment }\end{array}$ \\
\hline 1 & Bangladesh & 2484 & 860 & 0.35 \\
2 & Indonesia & 8185 & 5030 & 0.61 \\
3 & Sri Lanka & 1231 & 1870 & 1.52 \\
4 & Cambodia & 137 & 2450 & 17.94 \\
5 & Lao PDR & 107 & 4170 & 38.93 \\
6 & Malaysia & 2900 & 390 & 0.13 \\
7 & Pakistan & 3829 & 1620 & 0.42 \\
8 & Philippines & 2547 & 400 & 0.16 \\
9 & Singapore & 2759 & 800 & 0.29 \\
10 & Thailand & 3770 & 1870 & 0.50 \\
11 & Viet Nam & 1536 & 440 & 0.29 \\
12 & Belarus & 863 & 160 & 0.19 \\
13 & Russian Federation & 73,660 & 1340 & 0.02 \\
14 & United Arab Emirates & 3903 & 610 & 0.16 \\
15 & Azerbaijan & 742 & 270 & 0.36 \\
16 & Kazakhstan & 2368 & 560 & 0.24 \\
17 & Turkey & 9583 & 690 & 0.07 \\
& Weighted average & 7095 & 1384 & 0.195 \\
\hline
\end{tabular}

The summary was calculated based on raw data from CGIT database of AEI, which only contains investment worth $\$ 100$ million or above

Source: Authors' calculation

of transportation infrastructure investment from Chinese corporations through BRI projects among different countries are summarized in Table 5. In the case where the estimated ratio is surprisingly high, for instance, if the value of trade cost reduction is smaller than $-100 \%$, we assume that the corresponding reduction in trade cost is equivalent to $-100 \%$, which indicates that the trade margin between the two countries approximately equals zero.

\section{GTAP model}

The Global Trade Analysis Project (GTAP) model was adopted for the regional economic impact assessment. The model consists of 44 countries/regions and 57 economic sectors. Hence, the analysis was adopted for an ex-post assessment of the transportation infrastructure invested in the 17 countries by Chinese corporations in the period 2014-2020. 
The GTAP model was developed by Hertel (1997). It is a static and multiregional CGE model that has been widely adopted to evaluate the economic impact of international trade policies. The model was developed based on Walras's general equilibrium theory, and it has been extended to provide a realistic representation of the international trade given the introduction of transportation margin and saving institutions (Mukhopadhyay and Thomassin 2010). The GTAP model was developed primarily based on two sets of simultaneous equations. The first set represents the behavioral equations that were developed based on the microeconomic theory with a purpose to represent the economic behaviors of different agents. The second set of equation measures the accounting relationships among different agents (consumers, producers, government, and the rest of the world). Hence, the linkages were primarily developed based on macroeconomic theory. As Rose (1995) indicated, CGE models have advantages in that their modeling structure reflects multisectoral details. In addition, CGE models reflect an interdependency of various components, such as factor inputs, behavioral content, a reflection of the actions of prices and markets, nonlinearities, and incorporation of explicit constraints (Wei et al. 2019).

The GTAP 9 database was adopted for the CGE analysis. The data represents the world economy, and it has been extensively used for various impact assessments of global economic issues. The database also consists of information on import shares and tariff rates between partner countries. In this study, we evaluated the economic impact of trade margin reduction as a response to transportation infrastructure investment with a focus on the 42 BRI participant countries.

Given that the economic impacts of transportation infrastructure investment are likely to be different due to the various assumptions on the closure rule, our CGE analysis was conducted using both the short-run and the long-run closure rules to capture the various effects. Specifically, the short-run closure rule, also known as the Keynesian rule, assumes wage is fixed while labor supply and demand are determined endogenously. The exogenous shocks can lead to a change in labor supply and the labor force, which are adjusted until factor supply equals again at the initial wage. Conversely, the long-run closure rule, which is also known as the neoclassical rule, assumes full employment given that wage is determined endogenously. Although both closure rules present two extreme scenarios, such a comparative analysis helps us to gain a clearer understanding of the economic impacts of the investment under different assumptions, and the real-world impacts is expected to fall within the range of the two cases, given that the world economies tend to be a mix with both scenarios. The detailed discussions of the different sets of modeling institutions, including production, household, government, and foreign trade, can be seen from Hertel (1997) and Wei et al. (2019). The GTAP model enables us to analyze the economic impact measured in real GDP change, employment change, and the change of welfare. Economic welfare, which is measured in terms of equivalent variation, reflects the level of disposable income necessary to get to the new level of utility. Hence, the model enables us to evaluate to what extent the transportation infrastructure investment from China has affected the welfare change in various BRI countries. 


\section{Simulation results}

The investment in transportation infrastructure among 17 BRI countries during 2014-2020 has increased by $19.5 \%$ on average from its base level. It is also clear that the level of investment amount and the associated economic impacts (GDP and economic welfare) are quite uneven among different regions. We summarize the short- and long-run simulation results in Tables 6 and 7, respectively. The detailed country-specific results by both the short-run and the long-run effects are summarized in Appendices Tables 8 and 9, respectively.

We consider three scenarios in our study to compare the different economic impacts generated by intraregional, interregional, and combined trade costs reduction. In the scenario of intra-region, we observe that the real GDP is lower in 16 countries in the long run. In addition, 23 countries experience a loss in the economic welfare level. Specifically, most countries in Central and West Asia and non-EU countries in East Europe are negatively influenced by the intra-regional trade costs reduction both in the long-run and short-run equilibrium, as shown in Fig. 3a and d. Such outcomes may reflect the spillover effects (e.g., trade competition) from the improved transportation system among other regions. In particular, the impact of transportation infrastructure investment on intraregional trade costs was found negligible in Central and East Europe.

In the scenario of interregional impact, 28 countries were found to have positive real GDP growth. The results suggest that transportation infrastructure investment tends to significantly reduce interregional trade costs, which may generate an overall positive impact on the BRI countries' economies. However, such impacts are found quite uneven among the BRI countries, especially among South and Southeast Asia countries. For instance, Cambodia and Lao PDR experienced the most considerable impact from the BRI transportation infrastructure investment. Conversely, Singapore, Nepal, and Thailand received less benefit from the interregional trade cost reduction, as shown in Fig. $3 \mathrm{~b}$ and e.

The total impact of the trade cost reduction resulting from transportation infrastructure investment in BRI projects is summarized in the combined impact scenario. In general, the investment in transportation infrastructure generates an aggregate positive impact in BRI countries. However, the influence is found again, uneven among different regions.

As shown in Fig. 3c, 25 countries were found to have benefited from the trade cost reduction in the short run, given that the percent changes in real GDP are positive. For instance, the total economic impact in South and Southeast Asia is more substantial than in other regions due to the change of trade cost caused by transportation infrastructure investment in the long run. More precisely, in the short run and long run, the real GDP impacts were increased by $0.173 \%$ and $0.04 \%$ on average, respectively, compared with the case without such an investment. In particular, Lao PDR and Cambodia have experienced the highest growth in real GDP as a response to transportation infrastructure investment through BRI projects. Viet Nam and Thailand experienced the most extensive loss in real GDP of $-0.022 \%$ and $-0.031 \%$. 


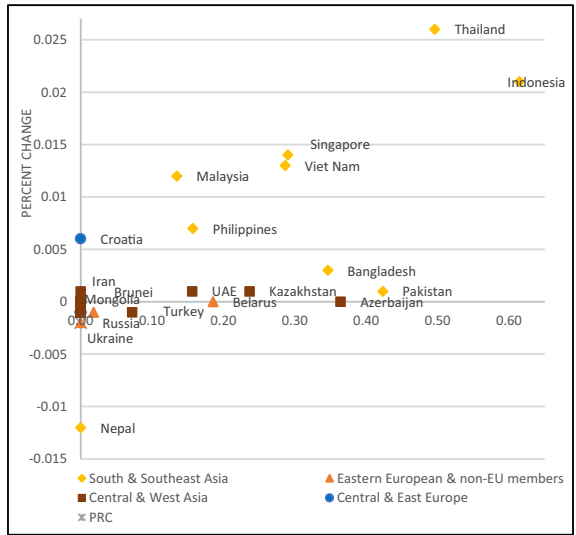

(a) Short-Run Intraregional Impact

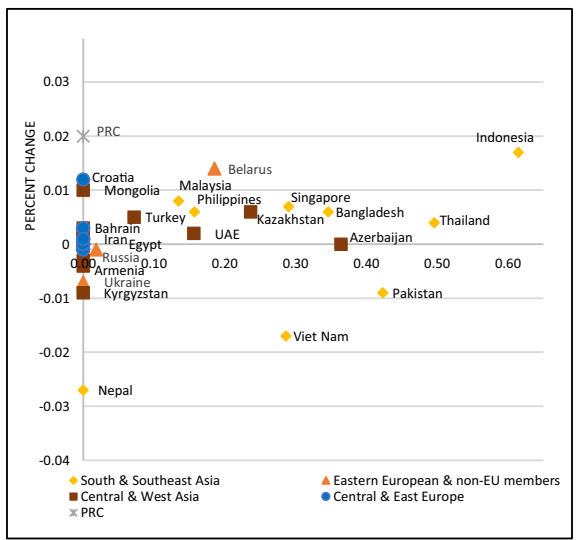

(c) Short-Run Combined Impact

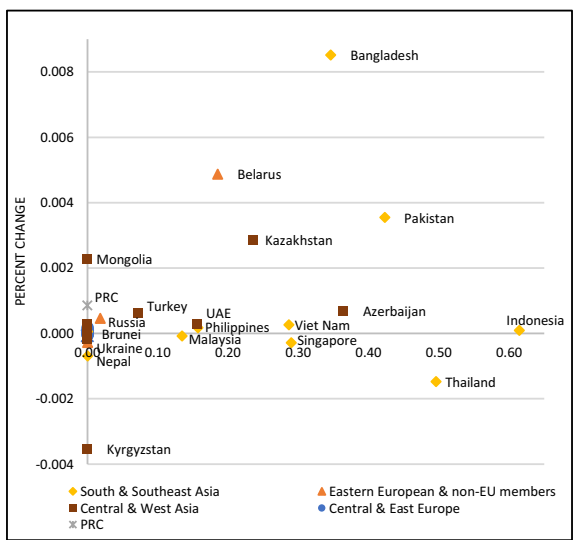

(e) Long-Run Interregional Impact

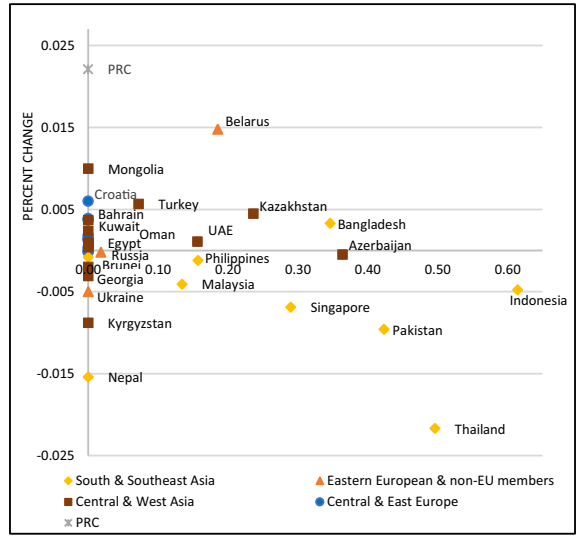

(b) Short-Run Interregional Impact

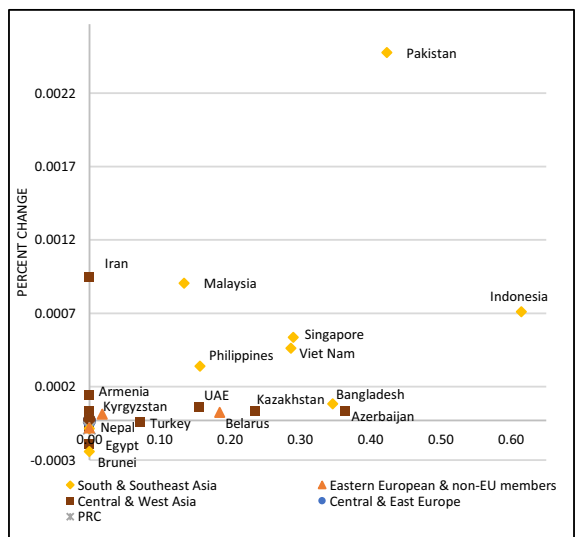

(d) Long-Run Intraregional Impact

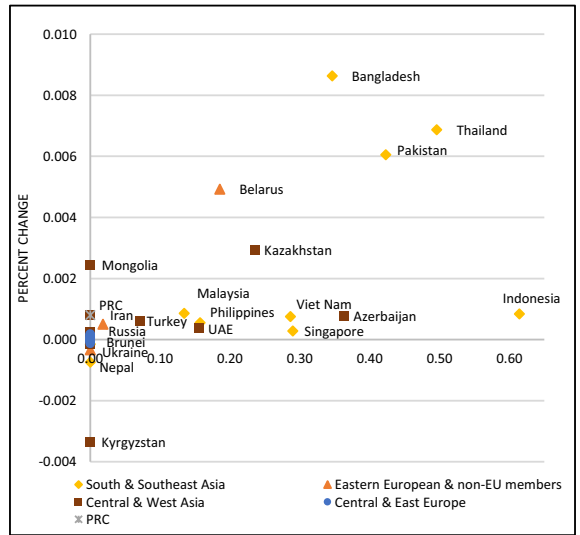

(f) Long-Run Combined Impact

Fig.3 GDP impact of transportation infrastructure investment from China. a Short-run intraregional impact. b Short-run interregional impact. c Short-run combined impact. d Long-run intraregional impact. e Long-run interregional impact. f Long-run combined impact 
Considering the long-run influence, we found that 32 countries benefit from the growth in real GDP, as demonstrated by Fig. 3f. However, compared with the short-run impact, the influence is relatively smaller. Such a difference may attribute to the different assumption of the closure rule. South and Southeast Asian countries are influenced significantly, with an average growth rate of $0.04 \%$ in real GDP. Meanwhile, we can observe that the average increasing rates in real GDP are lower in Central and West Asia (0.00032\%) and non-EU countries in East Europe $(0.0017 \%)$. The results also show that the economic impact of transportation infrastructure investment is minor in Central and East European countries. Specifically, the short- and long-run average real GDP growths are $0.0017 \%$ and $0.0002 \%$, respectively. Such a relatively lower impact is not surprising, given that the regions did not experience growth in infrastructure investment from China during 2014-2020.

In conclusion, our result suggests that China's BRI infrastructure investment plays a more dominant role in promoting regional economic growth, especially among South and Southeast Asia countries. The result also suggests that the BRI investment in transportation infrastructure enables Central and West Asian countries to be more involved in the international trade markets with China, Western Europe, and South Asia.

The welfare impact as a result of BRI infrastructure investment in transport is also evaluated. Detailed results of welfare level changes are summarized in Appendices Tables 8 and 9. Similar to the impact of real GDP, the impact of intraregional trade cost reduction is relatively small.

The combined impacts on welfare due to a trade cost reduction as a result of BRI transportation infrastructure investment also differ substantially among different regions. In general, the research finding reveals that around 29 countries experienced an increase in welfare in the short run as a result of a trade cost reduction

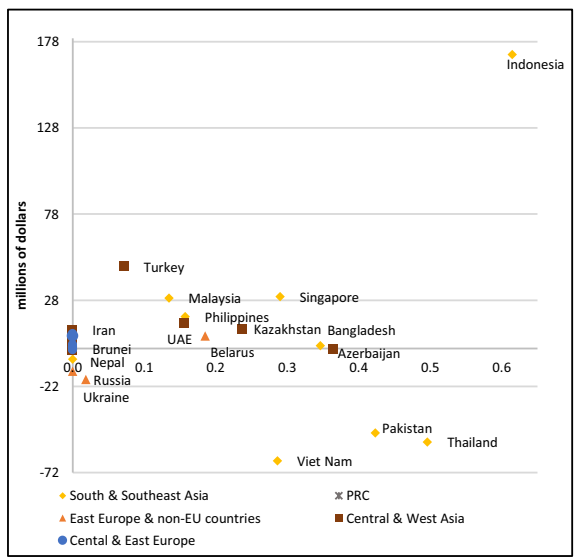

(a) Short-Run Combined Impact

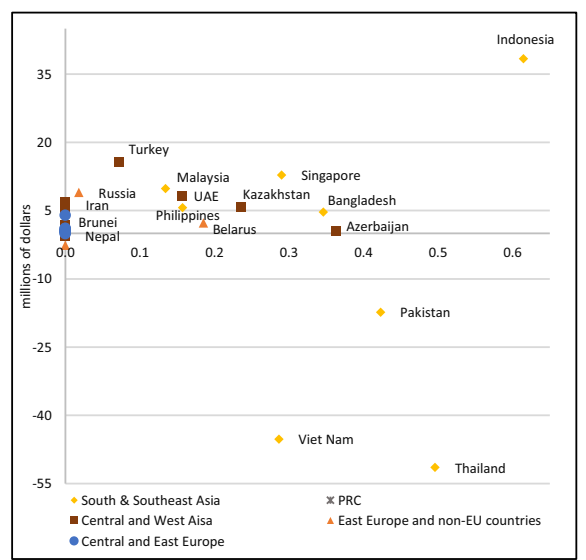

(b) Long-Run Combined Impact

Fig. 4 Welfare comparison based on the scenario of combined impact. a Short-run combined impact. b Long-run combined impact. Note: The horizontal axis represents the investment growth rate of transportation infrastructure in BRI projects 
due to the development of BRI projects. As shown in Fig. 4a, among all the BRI countries, the effect of the transportation infrastructure investment is found more substantial in Central and West Asia than the rest of the belt and road countries. Most countries (11 of 15) gain a positive welfare change in the short-run scenario. Countries, such as Lao PDR, Cambodia, and Singapore, received the largest gain in economic welfare among all the BRI participant countries.

The result demonstrates that 32 countries benefit from an increase in welfare in the long run. In addition, countries such as China, Lao PDR, Indonesia, and Turkey benefited the most in terms of economic welfare in the long-run scenario (as shown in Fig. 4b). Conversely, other countries, such as Thailand, Viet Nam, and Pakistan, experienced a more considerable decrease in economic welfare per capita, which is likely caused by the negative spillover effects of trade competition. Furthermore, the welfare effect is also found to be inconsistent with the long-run impact on GDP in some countries. For instance, countries such as Croatia, Saudi Arabia, Estonia, and Czech experienced a negative GDP growth rate, whereas a positive welfare impact was observed. Given that the labor market is assumed full employment in the long-run scenario, the domestic consumption market could be impacted by globalization with a wage increase, hence, may lead to lower welfare.

In addition, some countries, such as Thailand and Viet Nam, and Brunei Darussalam, have experienced a negative impact on both real GDP and economic welfare. According to the data from AEI, the growth of transportation infrastructure investment resulting from BRI projects is exceptionally high in Lao PDR and Cambodia, with $38.93 \%$ and $17.94 \%$, respectively. The negative impact on GDP growth may be caused by the negative spillover effect from other countries, given that the improved regional transportation connectivity may enhance their regional trade competitiveness.

Overall, the assessment reveals that most Central and West Asia countries appear to benefit from the positive change in welfare with the BRI transportation infrastructure investment, whereas the effect is uneven among South and Southeast Asian countries. Moreover, the trade cost reduction effect was found to be much smaller among European countries related to BRI projects.

\section{Conclusion}

This study contributes to the literature by developing a detailed evaluation framework that allows us to assess the economic impacts of investment in BRI transportation infrastructure projects from China. Unlike previous studies, we provide an ex-post assessment based on the actual investment data by capturing the effect of transportation infrastructure through the reduction of trade cost. Through the integration of econometric analysis with CGE modeling, our findings reveal that BRI transportation infrastructure investment has an overall positive effect among the belt and road countries, which is consistent with previous studies, such as Itakura 
(2014) and Zhai (2018). However, the impacts were found to vary substantially among different countries and regions. Central and West Asian countries were found to receive the largest gain in terms of growths in GDP and welfare, whereas the impacts were found to be relatively small in Central and Western Europe. The variation of growth rate in GDP and economic welfare are also found to be quite substantial in South and Southeast Asian countries.

This study provides at least two important policy implications. First, given that the combination of econometric analysis and CGE modeling enables us to achieve more realistic assessment outcomes of transportation infrastructure investment impact, such a modeling system may provide decision-makers with a more reliable and clear understanding of the regional economic impact of infrastructure investment and therefore improve the effectiveness of future decision-making on investment. Hence, it would be important to further improve the empirical impact assessment so that the decision-making of future investment strategies could be made more rationally.

Second, given that the economic impact of BRI transportation infrastructure investment was found to be dissimilar among different regions, future infrastructure development and investment plans need to be implemented more cautiously so as to a maximum benefit to the economy, welfare, as well as a maximum return to investment, could be achieved. In addition, as China moves to become the global leader in international development, in order to achieve the goal of building a human community with a shared future, more attention should be paid to regions with poorer infrastructure quality so that the development could be more equitable among the BRI countries.

One should note that our study has several limitations that need to be improved in future research endeavors. First, given that the elasticity of trade cost was estimated from the regression model based on the historical data, the accuracy could be affected by the quality of the statistical data. Therefore, future research could be expanded through conducting sensitivity analysis to further examine to what extent the research finding is consistent given the change of the base data. Second, the analysis can be improved if more specific data of infrastructure investment among different countries (particularly developing countries) can be collected and applied to calculate the magnitude of drivers of the economy. Third, due to the data limitation, our assessment does not differentiate the economic impact of infrastructure investment by different transportation modes (sea, rail and road, and air), which again deserves to be further investigated in future research so that the effectiveness of investment in various transportation modes can be analyzed. Last but not least, the existing CGE modeling framework was based on the standard GTAP model, which does not explicitly capture any spatial spillover effect of the transportation infrastructure investment. There may also some biases in the results of small countries. Therefore, it would be worthwhile incorporating more advanced methods, such as spatial econometric analysis into CGE analysis so that the effect of intra-regional trade and spatial effects of infrastructure investment can be captured. 


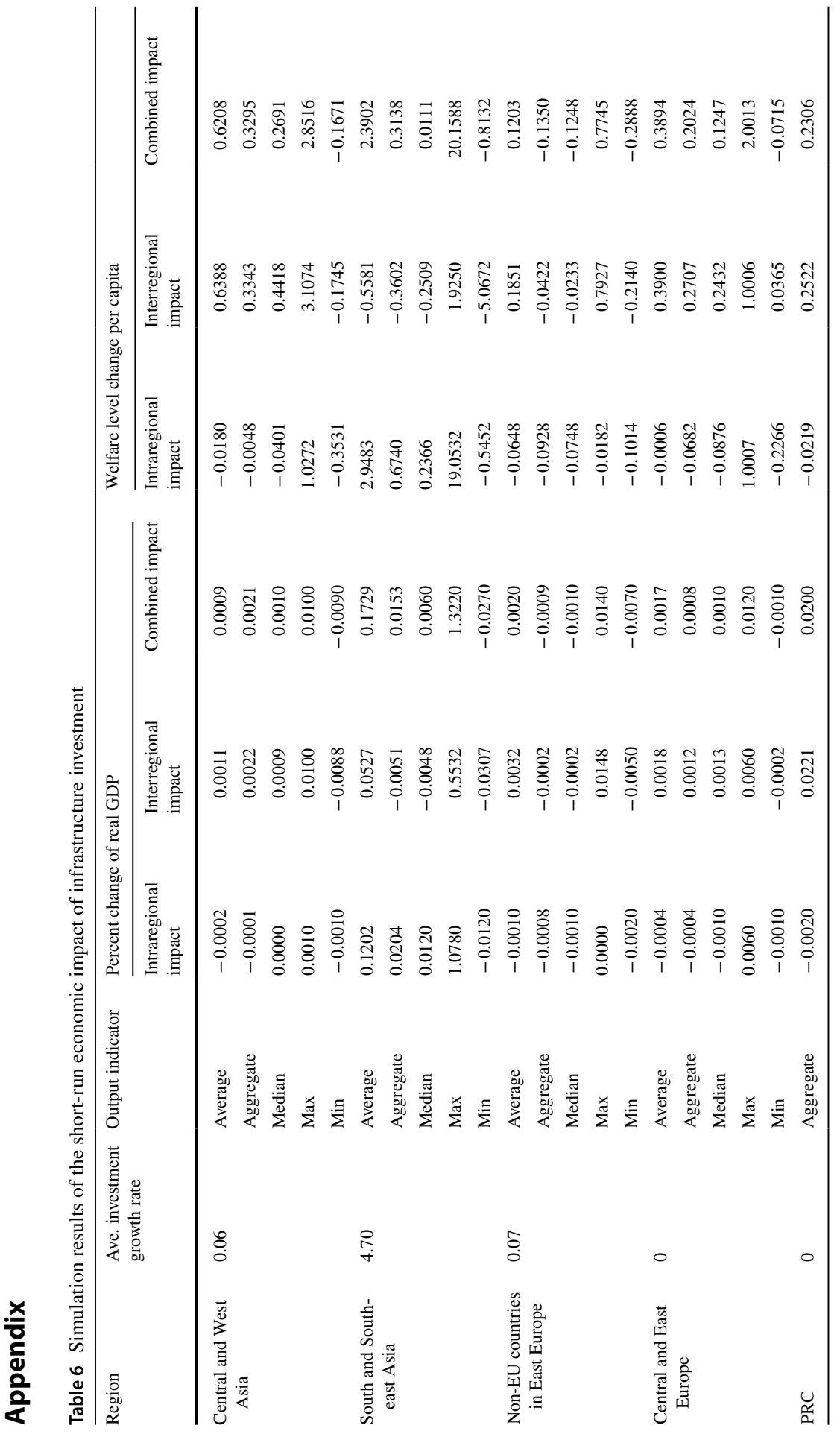




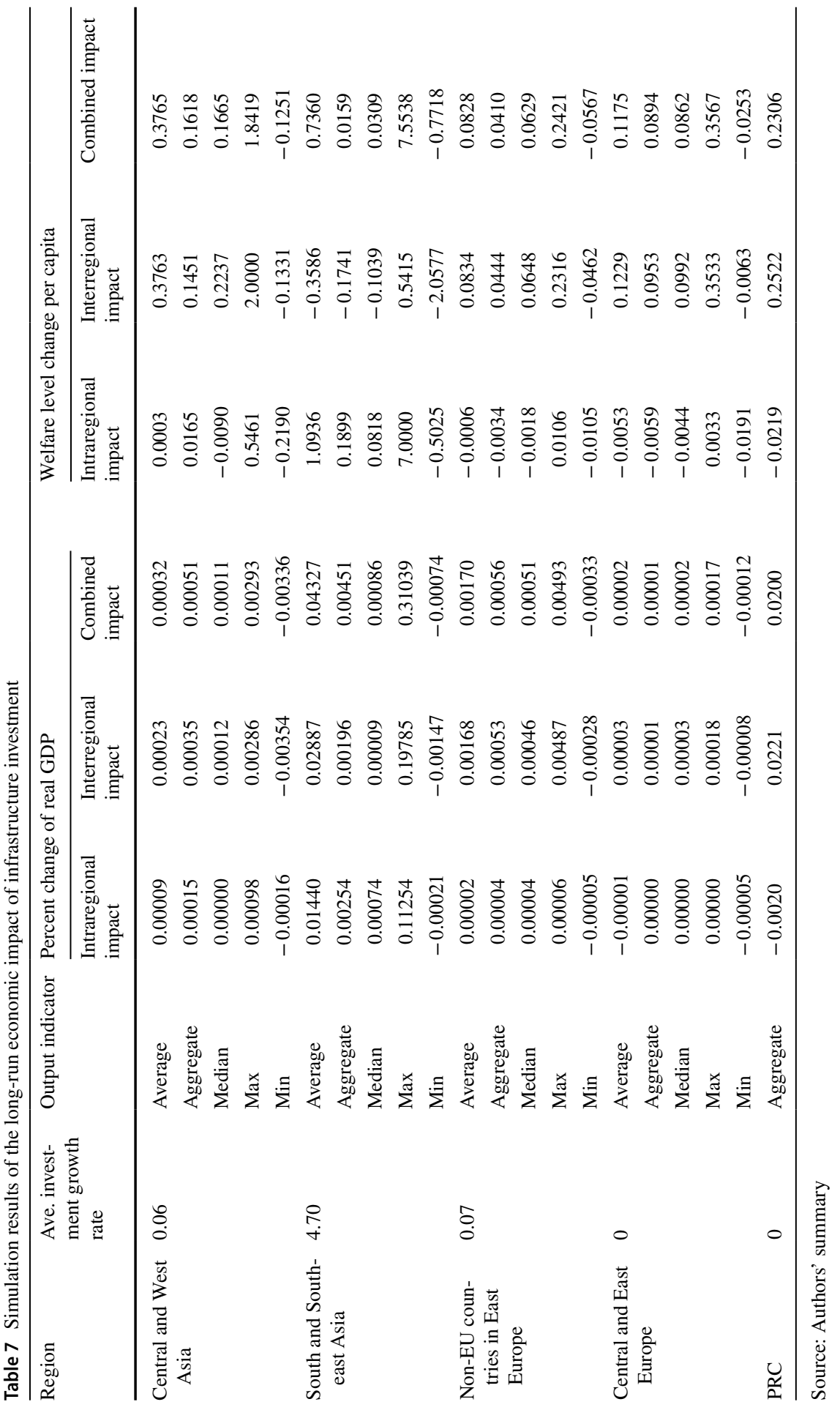




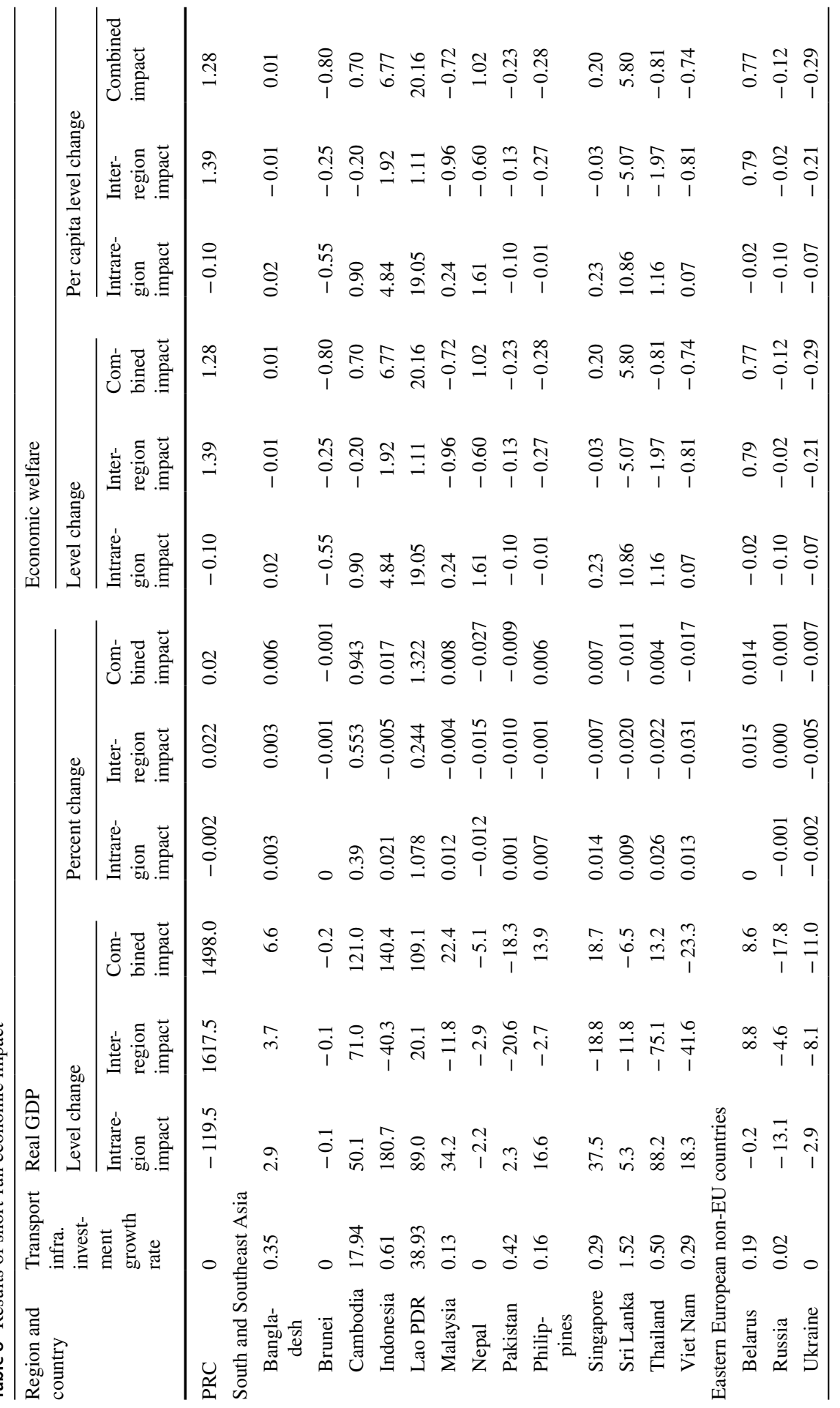




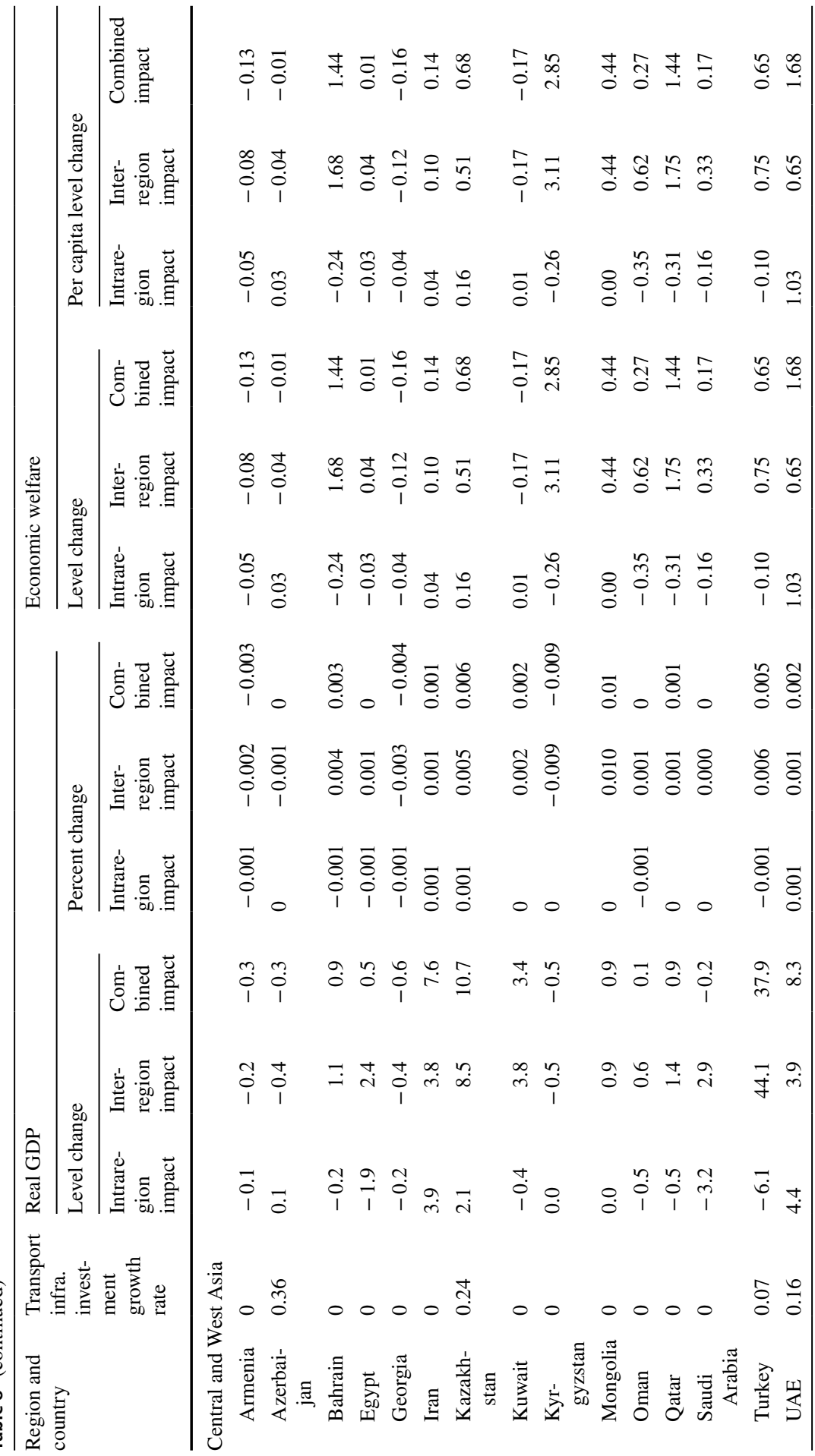




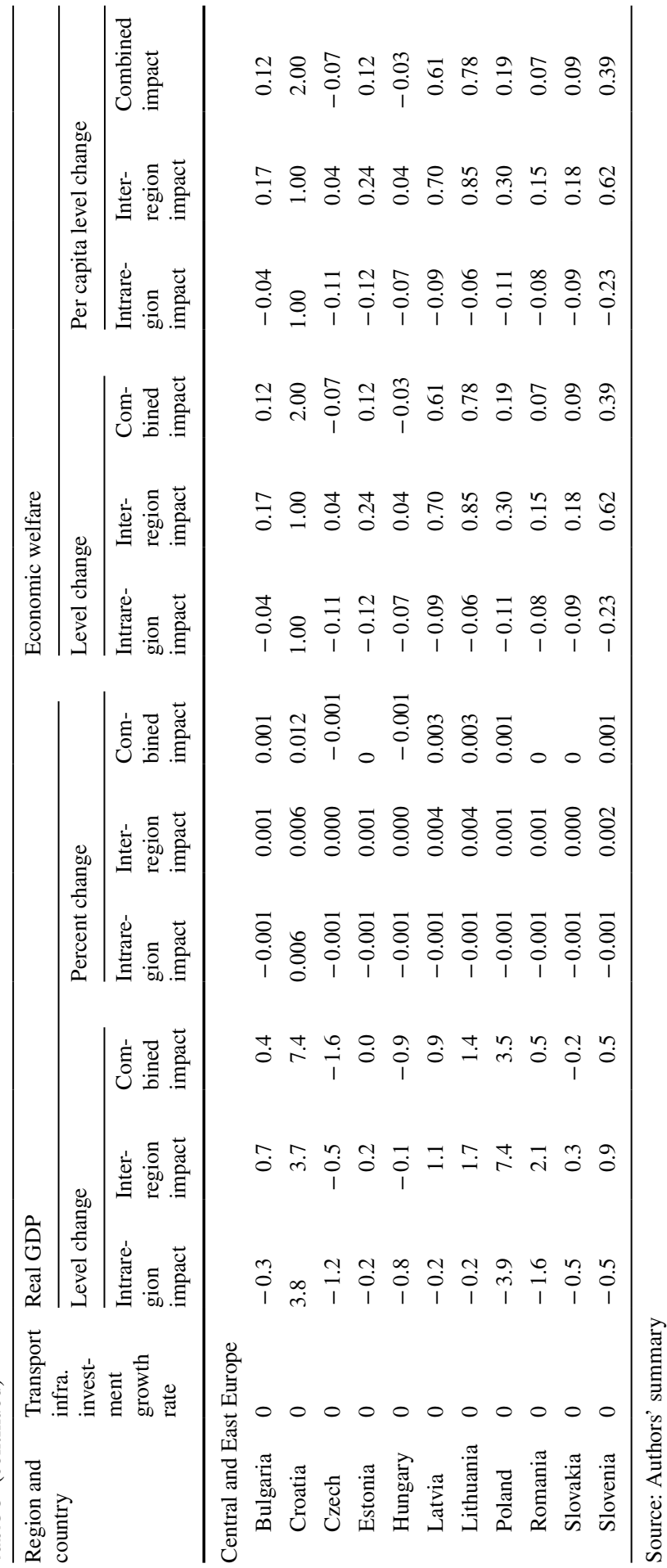




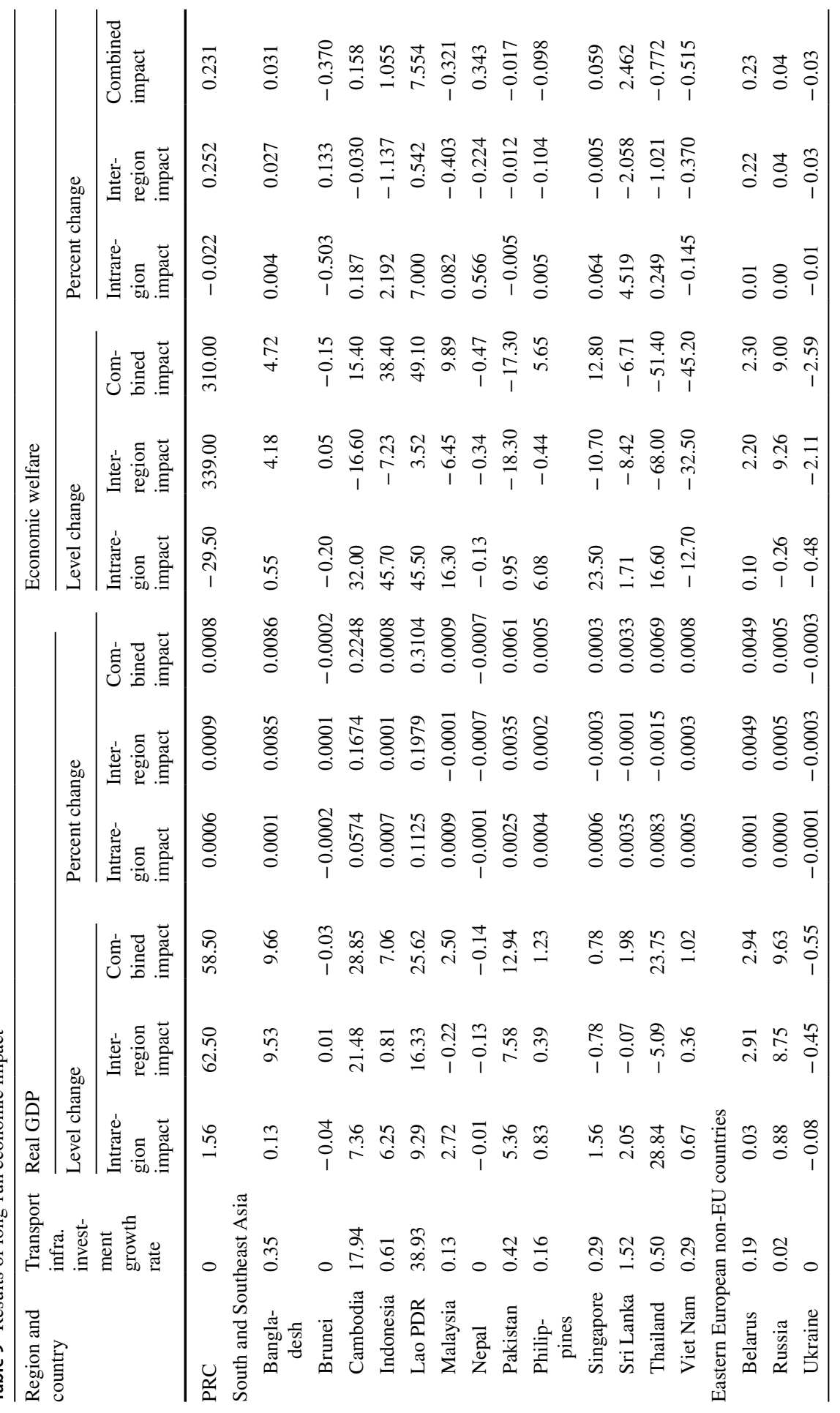




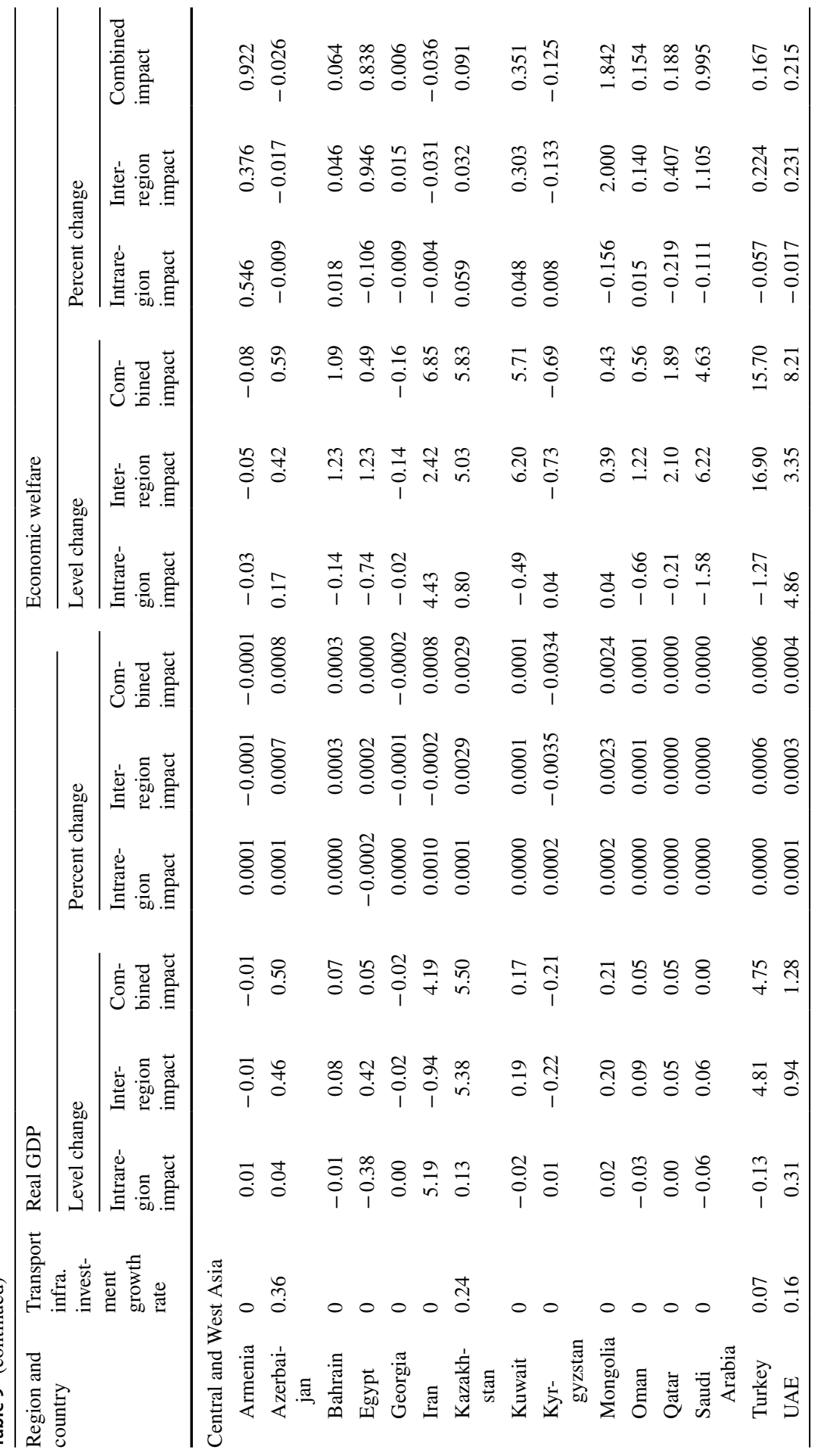




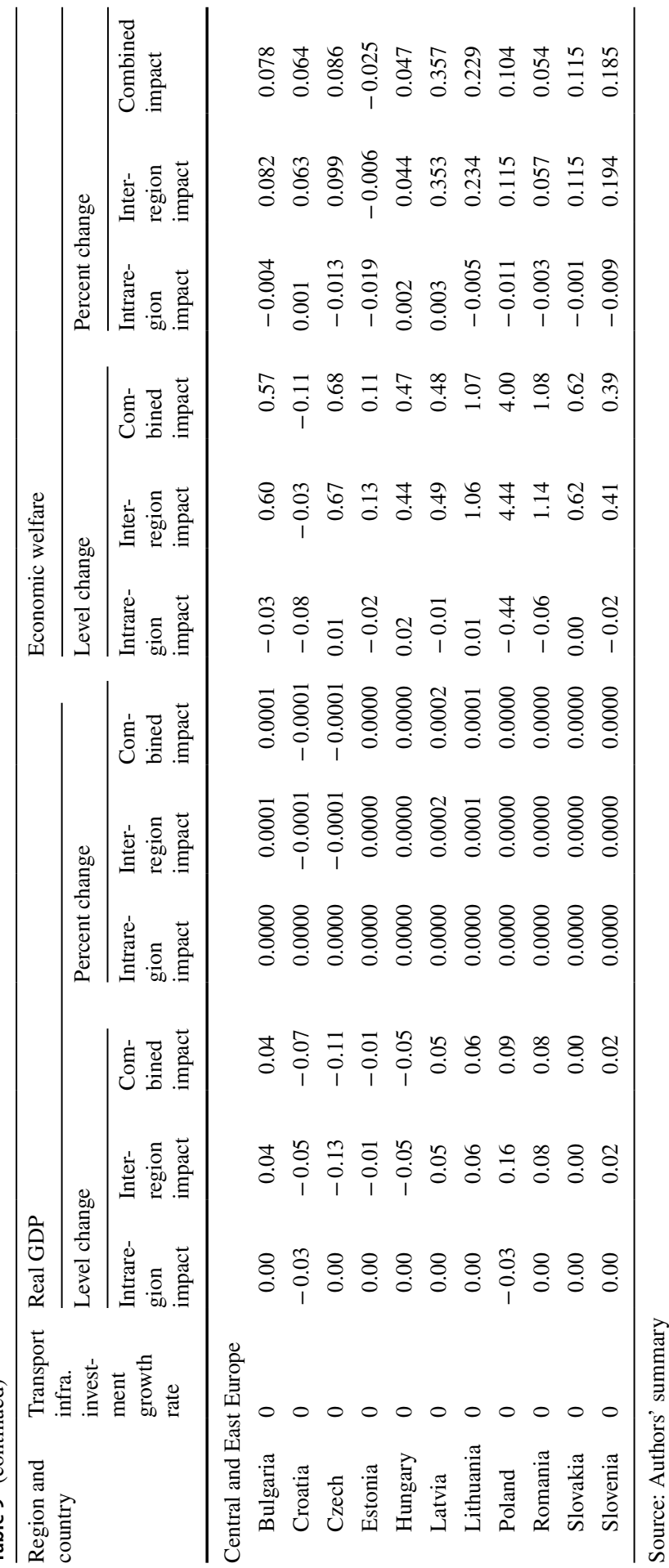




\section{References}

American Enterprise Institute (2018) China global investment tracker. https://www.aei.org/china-globalinvestment-tracker/. Accessed 29 June 2020

Aschauer DA (1989) Is public expenditure productive? J Monet Econ 23(2):177-200

Aschauer DA (1990) Why is infrastructure important? (Conference series; [proceedings]) (pp. 21-68). Federal Reserve Bank of Boston

Aschauer DA (1994) Infrastructure and macroeconomic performance: direct and indirect effects. Presented at the paper to OECD conference on capital formation and employment

Asian Development Bank (2015) Data library. https://data.adb.org/dataset/infrastructure-needs-asia-andpacific. Accessed 29 June 2020

Brooks DH, Hummels D (2009) Infrastructure's role in lowering Asia's trade costs: building for trade. Cheltenham: Edward Elgar Publishing

Centre For Geopolitics and Security in Realism Studies (2016) Strengths and challenges of China's "One Belt, One Road" initiative. http://cgsrs.org/publications/46. (assessed on 2/10/2021)

Chan MHT (2018) The belt and road initiative-the new silk road: a research agenda. Journal of Contemporary East Asia Studies 7(2):104-123

Chellaney B (2017) China's debt-trap diplomacy. Project Syndicate. January 23. https://www.proje ct-syndicate.org/commentary/china-one-belt-one-road-loans-debt-by-brahma-chellaney-2017-01 (assessed on 2/10/2021)

Chen Z, Haynes K (2014) Public surface transportation and regional output: a spatial panel approach. Pap Reg Sci 94(4):727-751

Chen Z, Xue J, Rose A, Haynes K (2016) Impact of high-speed rail investment on the economy and environment in China: a dynamic CGE analysis. Transportation Research Part A: Policy and Practice 92:232-245

Chong Z, Qin C, \& Chen Z (2019) Estimating the economic benefits of high-speed rail in China: a new perspective from the connectivity improvement. J Transp Land Use 12(1)

de Soyres F, Mulabdic A, Murray S, Rocha N, Ruta M (2018) How much will the belt and road initiative reduce trade costs? Washington DC: The World Bank

de Soyres F, Mulabdic A, Ruta M (2020) Common transport infrastructure: a quantitative model and estimates from the Belt and Road Initiative. J Dev Econ 143:102415

Donaldson D (2018) Railroads of the Raj: estimating the impact of transportation infrastructure. Am Econ Rev 108(4-5):899-934

Egger H, Kreickemeier U (2009) Firm heterogeneity and the labor market effects of trade liberalization. Int Econ Rev 50(1):187-216

Egger H, Kreickemeier U (2012) Fairness, trade, and inequality. J Int Econ 86(2):184-196

Felbermayr G, Prat J, Schmerer HJ (2011) Globalization and labor market outcomes: wage bargaining, search frictions, and firm heterogeneity. Journal of Economic Theory 146(1):39-73

Francois J, Manchin M (2013) Institutions, infrastructure, and trade. World Dev 46:165-175

Francois J, Manchin M, Pelkmans-Balaoing A (2009) Regional integration in Asia: the role of infrastructure. Chapter 7. In JF Francois, GP Wignaraja

Global Trade Analysis Project (Herrero AG, \& Xu J (2017) China's belt and road initiative: can Europe expect trade gains? China World Econ 25(6):84-99

Hertel TW (1997) Global trade analysis: modeling and applications. Cambridge University Press

Itakura K (2014) Impact of liberalization and improved connectivity and facilitation in ASEAN. J Asian Econ 35:2-11

Lall SV (2007) Infrastructure and regional growth, growth dynamics and policy relevance for India. Ann Reg Sci 41(3):581-599

Limao N, Venables AJ (2001) Infrastructure, geographical disadvantage, transport costs and trade. World Bank Econ Rev 15:451-479

Melitz MJ (2003) The impact of trade on intra-industry reallocations and aggregate industry productivity. Econometrica 71(6):1695-1725

Mukhopadhyay K, Thomassin PJ (2010) Economic and environmental impact of free trade in East and South East Asia. London: Springer

Mukwaya R, Mold A (2018) Modelling the economic impact of the China Belt and Road Initiative on East Africa. Conference: GTAP 21st annual conference on global economic analysis

Puga D (2002) European regional policies in light of recent location theories. J Econ Geogr 2(4):373-406 
Ramasamy B, Yeung MC (2019) China's one belt one road initiative: the impact of trade facilitation versus physical infrastructure on exports. World Econ 42(6):1673-1694

Rose A (1995) Input-output economics and computable general equilibrium models. Struct Chang Econ Dyn 6:295-304

Scissors D (2020) China's Global Investment in 2019: Going Out Goes Small. American Enterprise Institute. Washington, D.C. https://www.aei.org/research-products/report/chinas-global-inves tment-in-2019-going-out-goes-small/

Sheu JB, Kundu T (2018) Forecasting time-varying logistics distribution flows in the One Belt-One Road strategic context. Transp Res E Logist Transp Rev 117:5-22

Singh A (2020) The myth of 'debt-trap diplomacy' and realities of Chinese development finance. Third World Q 1-15

Stanley M (2018) https://www.morganstanley.com/ideas/china-belt-and-road

Stough RR, Rietveld P (1997) Institutional issues in transport systems. J Transp Geogr 5(3):207-214

Villafuerte J, Corong E, Zhuang J (2016) The one belt, one road initiative: impact on trade and growth. The 19th annual conference on global economic analysis. June. Washington DC: The World Bank

Wang C, Lim MK, Zhang X, Zhao L, Lee PTW (2020) Railway and road infrastructure in the Belt and Road Initiative countries: estimating the impact of transport infrastructure on economic growth. Transp Res A Policy Pract 134:288-307

Wei D, Chen Z, Rose A (2019) Estimating economic impacts of the US-South Korea free trade agreement. Econ Syst Res 31(3):305-323

Wen Y, Tsigas M (2017) Addressing excess capacity - the effect of China's FDI in the iron and steel industry in five central Asian states: a GTAP-FDI model perspective. Conference: GTAP 20st annual conference on global economic analysis

Yang G, Huang X, Huang J, Chen H (2020) Assessment of the effects of infrastructure investment under the belt and road initiative. China Econ Rev 60:101418

Zhai F (2018) China's belt and road initiative: a preliminary quantitative assessment. J Asian Econ 55:8

Zhang D (2018) The concept of 'community of common destiny' in China's diplomacy: meaning, motives and implications. Asia Pacific Policy Stud 5(2):196-207

Publisher's note Springer Nature remains neutral with regard to jurisdictional claims in published maps and institutional affiliations. 